\title{
A new iterative scheme for finding attractive points of $(\alpha, \beta)$-generalized hybrid set-valued mappings
}

\author{
Lili Chen ${ }^{\mathrm{a}, \mathrm{b}, *}, \mathrm{Lu}_{\mathrm{Gao}}^{\mathrm{b}}$, Yanfeng Zhao ${ }^{\mathrm{b}}$ \\ a Post Doctoral Station for Computer Science and Technology, Harbin University of Science and Technology, Harbin 150080, China. \\ ${ }^{b}$ Department of Mathematics, Harbin University of Science and Technology, Harbin 150080, China. \\ Communicated by P. Kumam
}

\begin{abstract}
In this paper, we first introduce the notions of $(\alpha, \beta)$-generalized hybrid set-valued mappings, strongly attractive points, attractive points and condition I'. Then we construct an iterative method for finding attractive points of $(\alpha, \beta)$-generalized hybrid set-valued mappings and obtain some convergence theorems of the proposed iterative scheme for $(\alpha, \beta)$-generalized hybrid set-valued mappings defined on a uniformly convex Banach space by using of condition I' and demi-compact property, respectively. (C)2017 All rights reserved.
\end{abstract}

Keywords: Generalized hybrid set-valued mapping, strongly attractive point, attractive point, uniformly convex Banach space, condition I'.

2010 MSC: 46B20, 46E30.

\section{Introduction and preliminaries}

Let $X$ be a Banach space and $C$ be a nonempty subset of $X$, and let $N$ and $R$ be the sets of positive integers and real numbers, respectively. We denote $C B(X)$ and $F(T)$ by the families of nonempty closed and bounded subsets and fixed points set of $\mathrm{T}$, respectively. $\mathrm{H}$ is Hausdorff metric defined by

$$
H(A, B)=\max \left\{\sup _{x \in A} d(x, B), \sup _{y \in B} d(y, A)\right\},
$$

where $d(x, B)=\inf \{\|x-z\|: z \in B\}$ and $d(y, A)=\inf \{\|y-z\|: z \in A\}$.

In 2010, Kocourek et al. [16] firstly introduced the notions of generalized hybrid mappings, which contains the classes of nonexpansive mappings, nonspreading mappings, and hybrid mappings. A mapping $\mathrm{T}: \mathrm{C} \rightarrow \mathrm{C}$ is called $(\alpha, \beta)$-generalized hybrid if there exist $\alpha, \beta \in R$ such that

$$
\alpha\|T x-T y\|^{2}+(1-\alpha)\|x-T y\|^{2} \leqslant \beta\|T x-y\|^{2}+(1-\beta)\|x-y\|^{2}
$$

\footnotetext{
*Corresponding author

Email addresses: cl12119@hotmail.com (Lili Chen), 1048560048@qq.com (Lu Gao), zhaoyanfeng@hrbust.edu.cn (Yanfeng Zhao)

doi:10.22436/jnsa.010.03.31
} 
for all $x, y \in C$. $T$ is called nonexpansive if $T$ is $(1,0)$-generalized hybrid; $T$ is said to be hybrid if $T$ is $\left(\frac{3}{2}, \frac{1}{2}\right)$-generalized hybrid [22], that is,

$$
3\|T x-T y\|^{2} \leqslant\|x-T y\|^{2}+\|T x-y\|^{2}+\|x-y\|^{2}, \text { for each } x, y \in C .
$$

$\mathrm{T}$ is called nonspreading if $\mathrm{T}$ is $(2,1)$-generalized hybrid [17], that is,

$$
2\|T x-T y\|^{2} \leqslant\|x-T y\|^{2}+\|T x-y\|^{2}, \text { for each } x, y \in C .
$$

In 2005, Sastry and Babu [19] introduced the Ishikawa iterative scheme for set-valued mappings in the following: let $\mathrm{T}: \mathrm{C} \rightarrow \mathrm{CB}(\mathrm{C})$ be a set-valued mapping and fix $\mathrm{p} \in \mathrm{F}(\mathrm{T})$,

$$
\left\{\begin{array}{l}
x_{1} \in C, \\
y_{n}=\left(1-\beta_{n}\right) x_{n}+\beta_{n} z_{n}
\end{array}\right.
$$

for all $n \in N$ and $\left\{\beta_{n}\right\} \subset(0,1), z_{n} \in T x_{n}$ with $\left\|z_{n}-p\right\|=d\left(p, T x_{n}\right)$ and

$$
\left\{\begin{array}{l}
x_{1} \in C, \\
x_{n+1}=\left(1-\beta_{n}\right) x_{n}+\beta_{n} z_{n}^{\prime}
\end{array}\right.
$$

for all $n \in N$ and $\left\{\alpha_{n}\right\} \subset(0,1), z_{n}^{\prime} \in T y_{n}$ with $\left\|z_{n}^{\prime}-p\right\|=d\left(p, T y_{n}\right)$.

In 2007, Agarwal et al. [2] introduced an iteration scheme for single-valued mappings. This iteration scheme is as the following:

$$
\left\{\begin{array}{l}
x_{1} \in C \\
x_{n+1}=\left(1-\alpha_{n}\right) T x_{n}+\alpha_{n} T y_{n} \\
y_{n}=\left(1-\beta_{n}\right) x_{n}+\beta_{n} T x_{n}
\end{array}\right.
$$

for all $n \in N$ and $\left\{\alpha_{n}\right\},\left\{\beta_{n}\right\} \subset(0,1)$.

In 2011, Takahashi and Yao [24] got fixed point theorems and ergodic theorems for nonlinear mappings in Hilbert spaces. Kocourek et al. [16] also obtained fixed point theorems and weak convergence theorems of the Mann's iteration for generalized hybrid mappings in Hilbert spaces. This iteration scheme is as the following:

$$
\left\{\begin{array}{l}
x_{1} \in C \\
x_{n+1}=\alpha_{n} x_{n}+\left(1-\alpha_{n}\right) T x_{n}
\end{array}\right.
$$

for all $n \in N$ and $\left\{\alpha_{n}\right\} \subset(0,1)$.

In 2012, Khan and Yildirim [15] introduced a multi-valued mapping version of the iteration scheme (1.1). This iteration scheme is as the following:

$$
\left\{\begin{array}{l}
x_{1} \in C \\
x_{n+1}=\left(1-\alpha_{n}\right) v_{n}+\alpha_{n} u_{n} \\
y_{n}=\left(1-\beta_{n}\right) x_{n}+\beta_{n} v_{n}
\end{array}\right.
$$

for all $n \in N$ and $v_{n} \in P_{T}\left(x_{n}\right), u_{n} \in P_{T}\left(y_{n}\right)$ and $\left\{\alpha_{n}\right\},\left\{\beta_{n}\right\} \subset(0,1)$.

In 2015, Zheng [26] obtained convergence theorems of the Ishikawa iteration for $(\alpha, \beta)$-generalized hybrid mappings. This iteration scheme is as the following:

$$
\left\{\begin{array}{l}
x_{1} \in C, \\
x_{n+1}=\left(1-\alpha_{n}\right) x_{n}+\alpha_{n} T y_{n}, \\
y_{n}=\left(1-\beta_{n}\right) x_{n}+\beta_{n} T x_{n}
\end{array}\right.
$$

for all $n \in N$ and $\left\{\alpha_{n}\right\},\left\{\beta_{n}\right\} \subset(0,1)$. 
A great deal of results involving $(\alpha, \beta)$-generalized hybrid mappings, nonexpansive mappings and fixed points were obtained by several authors [1, 3, 4, 6-10, 12-14, 18, 21, 23].

$\mathrm{T}: \mathrm{C} \rightarrow \mathrm{CB}(\mathrm{C})$ is said to be demi-compact [11] if for each sequence $\left\{x_{n}\right\}$ in $\mathrm{C}$ such that

$$
\lim _{n \rightarrow \infty} d\left(x_{n}, T x_{n}\right)=0,
$$

then there exists a subsequence $\left\{x_{n_{k}}\right\}$ of $\left\{x_{n}\right\}$ such that

$$
\lim _{k \rightarrow \infty} x_{n_{k}}=x \in C
$$

We now recall some basis definitions and useful lemmas.

Definition 1.1 ([20]). Let $X$ be a Banach space and $C$ be a nonempty subset of $X$. A mapping $T: C \rightarrow C$ is said to satisfy condition $I$ if there is a nondecreasing function $f:[0, \infty) \rightarrow[0, \infty)$ with $f(0)=0$ and $f(a)>0$ for each $a \in(0,+\infty)$ such that

$$
\|x-T x\| \geqslant f(d(x, A(T))) \text { for each } x \in C,
$$

where $d(x, A(T))=\inf \{\|x-p\|: p \in A(T)\}$.

Definition 1.2 ([5]). A Banach space $X$ is said to be uniformly convex if for each $\varepsilon \in[0,2]$, there exists $\delta_{\varepsilon}>0$ such that

$$
\|x\|=\|y\|=1 \Rightarrow\left\|\frac{x+y}{2}\right\|<1-\delta_{\varepsilon},
$$

whenever $\|x-y\| \geqslant \varepsilon$.

Lemma 1.3 ([25]). Let $\mathrm{q}>1$ and $\mathrm{r}>0$ be two fixed real numbers. Then a Banach space $\mathrm{X}$ is uniformly convex if and only if there exists a continuous strictly increasing convex function $\mathrm{g}:[0, \infty) \rightarrow[0, \infty)$ with $\mathrm{g}(0)=0$ such that

$$
\|\lambda x+(1-\lambda) y\|^{q} \leqslant \lambda\|x\|^{q}+(1-\lambda)\|y\|^{q}-\omega_{q}(\lambda) g(\|x-y\|)
$$

for each $x, y \in B_{r}(0)=\{x \in X:\|x\| \leqslant r\}$ and $\lambda \in[0,1]$, where $\omega_{q}(\lambda)=\lambda^{q}(1-\lambda)+\lambda(1-\lambda)^{q}$.

In this paper, we first introduce the notions of $(\alpha, \beta)$-generalized hybrid set-valued mappings, strongly attractive points, attractive points and condition $\mathrm{I}^{\prime}$. Moreover, we propose a new iteration for finding attractive points of an $(\alpha, \beta)$-generalized hybrid set-valued mapping and obtain convergence theorems of an $(\alpha, \beta)$-generalized hybrid set-valued mapping. This iterative scheme is denoted by the following:

$$
\left\{\begin{array}{l}
x_{1} \in C \\
x_{n+1}=\left(1-\alpha_{n}\right) x_{n}+\alpha_{n} u_{n} \\
z_{n}=\left(1-\gamma_{n}\right) y_{n}+\gamma_{n} w_{n}
\end{array}\right.
$$

for all $n \in N$ and $u_{n} \in T z_{n}, y_{n} \in T\left(\left(1-\beta_{n}\right) x_{n}+\beta_{n} w_{n}\right), w_{n} \in T x_{n},\left\{\alpha_{n}\right\},\left\{\beta_{n}\right\},\left\{\gamma_{n}\right\} \subset(0,1)$.

\section{Main results}

We begin with this section by introducing the notions of $(\alpha, \beta)$-generalized hybrid set-valued mappings, strongly attractive points, and attractive points.

Definition 2.1. A mapping $T: C \rightarrow C$ is called $(\alpha, \beta)$-generalized hybrid set-valued if there exist $\alpha, \beta \in R$ such that

$$
\alpha \mathrm{H}^{2}(T x, T y)+(1-\alpha) d^{2}(x, T y) \leqslant \beta d^{2}(y, T x)+(1-\beta)\|x-y\|^{2}
$$

for all $x, y \in C$. 
Definition 2.2. Let $X$ be a Banach space and $C$ be a nonempty subset of $X$, and let $T: C \rightarrow 2^{X} \backslash\{\emptyset\}$. A point $p \in X$ is called a strongly attractive point of $T$ if for all $x \in C$, we have

$$
H(p, T x) \leqslant\|p-x\| .
$$

We denote by $S A(T)$ the set of all strongly attractive points of $T$, that is,

$$
S A(T)=\{p \in X: H(p, T x) \leqslant\|p-x\| \text { for all } x \in C\} .
$$

Definition 2.3. Let $X$ be a Banach space and $C$ be a nonempty subset of $X$, and let $T: C \rightarrow 2^{X} \backslash\{\emptyset\}$. A point $p \in X$ is called an attractive point of $T$ if for all $x \in C$, we have

$$
d(p, T x) \leqslant\|p-x\| .
$$

We denote by $A(T)$ the set of all attractive points of $T$, that is,

$$
A(T)=\{p \in X: d(p, T x) \leqslant\|p-x\| \text { for all } x \in C\} .
$$

It is obvious that $S A(T) \subseteq A(T)$. Now, using condition I and the set $S A(T)$ we can introduce the notion of condition $\mathrm{I}^{\prime}$.

Definition 2.4. Let $X$ be a Banach space and $C$ be a nonempty subset of $X$. A mapping $T: C \rightarrow C$ is said to satisfy condition $I^{\prime}$, if there is a nondecreasing function $f:[0, \infty) \rightarrow[0, \infty)$ with $f(0)=0$ and $f(a)>0$ for each $a \in(0,+\infty)$ such that

$$
\|x-T x\| \geqslant f(d(x, S A(T))) \text { for each } x \in C,
$$

where $d(x, S A(T))=\inf \{\|x-p\|: p \in S A(T)\}$.

It is not difficult to see that if a mapping $T$ satisfies condition $I^{\prime}$, then $T$ satisfies condition I. Next, we discuss convergence theorems of an $(\alpha, \beta)$-generalized hybrid set-valued mapping in a uniformly convex Banach space.

Theorem 2.5. Let $\mathrm{C}$ be a nonempty closed convex subset of a uniformly convex Banach space $\mathrm{X}$ and let $\mathrm{T}: \mathrm{C} \rightarrow$ $\mathrm{CB}(\mathrm{C})$ be an $(\alpha, \beta)$-generalized hybrid set-valued mapping with $\mathrm{SA}(\mathrm{T}) \neq \emptyset$. Suppose that the sequence $\left\{x_{n}\right\}$ is generated by the iterative scheme (1.2), where $u_{n} \in T z_{n}, y_{n} \in T\left(\left(1-\beta_{n}\right) x_{n}+\beta_{n} w_{n}\right), w_{n} \in T x_{n},\left\{\alpha_{n}\right\}$, and $\left\{\beta_{\mathrm{n}}\right\}$ and $\left\{\gamma_{\mathrm{n}}\right\}$ belong to $(0,1)$ such that

$$
\liminf _{n \rightarrow \infty} \alpha_{n} \beta_{n}\left(1-\beta_{n}\right)\left(1-\gamma_{n}\right)>0 .
$$

Then the following conclusions hold:

(1) the sequence $\left\{x_{n}\right\}$ is bounded;

(2) $\lim _{n \rightarrow \infty}\left\|x_{n}-p\right\|$ exists for each $p \in S A(T)$;

(3) $\lim _{n \rightarrow \infty} d\left(x_{n}, T x_{n}\right)=0$.

Proof. Let $p \in S A(T)$, we have

$$
\begin{aligned}
\left\|y_{n}-p\right\| & \leqslant H\left(T\left(\left(1-\beta_{n}\right) x_{n}+\beta_{n} w_{n}\right), p\right) \\
& \leqslant\left\|\left(1-\beta_{n}\right) x_{n}+\beta_{n} w_{n}-p\right\| \\
& \leqslant\left(1-\beta_{n}\right)\left\|x_{n}-p\right\|+\beta_{n}\left\|w_{n}-p\right\| \\
& \leqslant\left(1-\beta_{n}\right)\left\|x_{n}-p\right\|+\beta_{n} H\left(T x_{n}, p\right) \\
& \leqslant\left(1-\beta_{n}\right)\left\|x_{n}-p\right\|+\beta_{n}\left\|x_{n}-p\right\| \\
& =\left\|x_{n}-p\right\|,
\end{aligned}
$$




$$
\begin{aligned}
\left\|z_{n}-p\right\| & =\left\|\left(1-\gamma_{n}\right) y_{n}+\gamma_{n} w_{n}-p\right\| \\
& \leqslant\left(1-\gamma_{n}\right)\left\|y_{n}-p\right\|+\gamma_{n}\left\|w_{n}-p\right\| \\
& \leqslant\left(1-\gamma_{n}\right)\left\|y_{n}-p\right\|+\gamma_{n} H\left(T x_{n}, p\right) \\
& \leqslant\left(1-\gamma_{n}\right)\left\|y_{n}-p\right\|+\gamma_{n}\left\|x_{n}-p\right\| \\
& \leqslant\left(1-\gamma_{n}\right)\left\|x_{n}-p\right\|+\gamma_{n}\left\|x_{n}-p\right\| \\
& =\left\|x_{n}-p\right\|,
\end{aligned}
$$

and

$$
\begin{aligned}
\left\|x_{n+1}-p\right\| & =\left\|\left(1-\alpha_{n}\right) x_{n}+\alpha_{n} u_{n}-p\right\| \\
& \leqslant\left(1-\alpha_{n}\right)\left\|x_{n}-p\right\|+\alpha_{n}\left\|u_{n}-p\right\| \\
& \leqslant\left(1-\alpha_{n}\right)\left\|x_{n}-p\right\|+\alpha_{n} H\left(T z_{n}, p\right) \\
& \leqslant\left(1-\alpha_{n}\right)\left\|x_{n}-p\right\|+\alpha_{n}\left\|z_{n}-p\right\| \\
& \leqslant\left(1-\alpha_{n}\right)\left\|x_{n}-p\right\|+\alpha_{n}\left\|x_{n}-p\right\| \\
& =\left\|x_{n}-p\right\|,
\end{aligned}
$$

which implies the sequence $\left\{\left\|x_{n}-p\right\|\right\}$ is nonincreasing. Therefore, the limit $\lim _{n \rightarrow \infty}\left\|x_{n}-p\right\|$ exists for each $p \in S A(T)$. Hence the sequence $\left\{x_{n}\right\}$ is bounded.

Now we show the last conclusion holds. Let $r \geqslant\left\|x_{1}-p\right\|$, then we get

$$
\begin{aligned}
& \left\|u_{n}-p\right\| \leqslant H\left(T z_{n}, p\right) \leqslant\left\|z_{n}-p\right\| \leqslant\left\|x_{n}-p\right\| \leqslant r, \\
& \left\|y_{n}-p\right\| \leqslant\left\|x_{n}-p\right\| \leqslant r,
\end{aligned}
$$

and

$$
\left\|w_{n}-p\right\| \leqslant H\left(T x_{n}, p\right) \leqslant\left\|x_{n}-p\right\| \leqslant r .
$$

It follows from Lemma 1.3 that

$$
\begin{aligned}
\left\|x_{n+1}-p\right\|^{2}= & \left\|\left(1-\alpha_{n}\right) x_{n}+\alpha_{n} u_{n}-p\right\|^{2} \\
\leqslant & \left(1-\alpha_{n}\right)\left\|x_{n}-p\right\|^{2}+\alpha_{n}\left\|u_{n}-p\right\|^{2} \\
\leqslant & \left(1-\alpha_{n}\right)\left\|x_{n}-p\right\|^{2}+\alpha_{n} H^{2}\left(T z_{n}, p\right) \\
\leqslant & \left(1-\alpha_{n}\right)\left\|x_{n}-p\right\|^{2}+\alpha_{n}\left\|z_{n}-p\right\|^{2} \\
= & \left(1-\alpha_{n}\right)\left\|x_{n}-p\right\|^{2}+\alpha_{n}\left\|\left(1-\gamma_{n}\right) y_{n}+\gamma_{n} w_{n}-p\right\|^{2} \\
\leqslant & \left(1-\alpha_{n}\right)\left\|x_{n}-p\right\|^{2}+\alpha_{n}\left(1-\gamma_{n}\right)\left\|y_{n}-p\right\|^{2}+\alpha_{n} \gamma_{n}\left\|w_{n}-p\right\|^{2} \\
\leqslant & \left(1-\alpha_{n}\right)\left\|x_{n}-p\right\|^{2}+\alpha_{n}\left(1-\gamma_{n}\right)\left\|y_{n}-p\right\|^{2}+\alpha_{n} \gamma_{n} H^{2}\left(T x_{n}, p\right) \\
\leqslant & \left(1-\alpha_{n}\right)\left\|x_{n}-p\right\|^{2}+\alpha_{n}\left(1-\gamma_{n}\right)\left\|y_{n}-p\right\|^{2}+\alpha_{n} \gamma_{n}\left\|x_{n}-p\right\|^{2} \\
\leqslant & \left(1-\alpha_{n}\right)\left\|x_{n}-p\right\|^{2}+\alpha_{n}\left(1-\gamma_{n}\right) H^{2}\left(T\left(\left(1-\beta_{n}\right) x_{n}+\beta_{n} w_{n}\right), p\right)+\alpha_{n} \gamma_{n}\left\|x_{n}-p\right\|^{2} \\
\leqslant & \left(1-\alpha_{n}\right)\left\|x_{n}-p\right\|^{2}+\alpha_{n}\left(1-\gamma_{n}\right)\left\|\left(1-\beta_{n}\right)\left(x_{n}-p\right)+\beta_{n}\left(w_{n}-p\right)\right\|^{2}+\alpha_{n} \gamma_{n}\left\|x_{n}-p\right\|^{2} \\
\leqslant & \left(1-\alpha_{n}+\alpha_{n} \gamma_{n}\right)\left\|x_{n}-p\right\|^{2}+\alpha_{n}\left(1-\gamma_{n}\right)\left[\left(1-\beta_{n}\right)\left\|x_{n}-p\right\|^{2}\right. \\
+ & \left.\beta_{n}\left\|w_{n}-p\right\|^{2}-\beta_{n}\left(1-\beta_{n}\right) g\left(\left\|w_{n}-x_{n}\right\|\right)\right] \\
\leqslant & \left(1-\alpha_{n}+\alpha_{n} \gamma_{n}\right)\left\|x_{n}-p\right\|^{2}+\alpha_{n}\left(1-\gamma_{n}\right)\left[\left(1-\beta_{n}\right)\left\|x_{n}-p\right\|^{2}\right. \\
& \left.+\beta_{n} H^{2}\left(T x_{n}, p\right)-\beta_{n}\left(1-\beta_{n}\right) g\left(\left\|w_{n}-x_{n}\right\|\right)\right] \\
\leqslant & \left(1-\alpha_{n}+\alpha_{n} \gamma_{n}\right)\left\|x_{n}-p\right\|^{2}+\alpha_{n}\left(1-\gamma_{n}\right)\left[\left(1-\beta_{n}\right)\left\|x_{n}-p\right\|^{2}\right. \\
& \left.+\beta_{n}\left\|x_{n}-p\right\|^{2}-\beta_{n}\left(1-\beta_{n}\right) g\left(\left\|w_{n}-x_{n}\right\|\right)\right] \\
= & \left\|x_{n}-p\right\|^{2}-\alpha_{n} \beta_{n}\left(1-\beta_{n}\right)\left(1-\gamma_{n}\right) g\left(\left\|w_{n}-x_{n}\right\|\right)
\end{aligned}
$$




$$
\leqslant\left\|x_{n}-p\right\|^{2}-\alpha_{n} \beta_{n}\left(1-\beta_{n}\right)\left(1-\gamma_{n}\right) g\left(d\left(x_{n}, T x_{n}\right)\right) .
$$

Then

$$
\alpha_{n} \beta_{n}\left(1-\beta_{n}\right)\left(1-\gamma_{n}\right) g\left(d\left(x_{n}, T x_{n}\right)\right) \leqslant\left\|x_{n}-p\right\|^{2}-\left\|x_{n+1}-p\right\|^{2} .
$$

Hence

$$
\sum_{n=1}^{\infty} \alpha_{n} \beta_{n}\left(1-\beta_{n}\right)\left(1-\gamma_{n}\right) g\left(d\left(x_{n}, T x_{n}\right)\right) \leqslant\left\|x_{1}-p\right\|^{2}<+\infty .
$$

In view of

$$
\liminf _{n \rightarrow \infty} \alpha_{n} \beta_{n}\left(1-\beta_{n}\right)\left(1-\gamma_{n}\right)>0
$$

which implies

$$
\lim _{n \rightarrow \infty} g\left(d\left(x_{n}, T x_{n}\right)\right)=0 .
$$

Since $g$ is continuous, strictly increasing, convex, and $g(0)=0$, we have

$$
\lim _{n \rightarrow \infty} d\left(x_{n}, T x_{n}\right)=0,
$$

which completes the proof.

By Theorem 2.5, we show a strong convergence theorem of an $(\alpha, \beta)$-generalized hybrid set-valued mapping in a uniformly convex Banach space.

Theorem 2.6. Let $\mathrm{C}$ be a nonempty closed convex subset of a uniformly convex Banach space $\mathrm{X}$ and let $\mathrm{T}: \mathrm{C} \rightarrow$ $\mathrm{CB}(\mathrm{C})$ be an $(\alpha, \beta)$-generalized hybrid set-valued mapping with $\mathrm{SA}(\mathrm{T}) \neq \emptyset$ and satisfy condition $\mathrm{I}^{\prime}$. Suppose that the sequence $\left\{x_{n}\right\}$ is generated by the iterative scheme (1.2), where $u_{n} \in T z_{n}, y_{n} \in T\left(\left(1-\beta_{n}\right) x_{n}+\beta_{n} w_{n}\right)$, $w_{n} \in T x_{n}$, and the sequences $\left\{\alpha_{n}\right\},\left\{\beta_{n}\right\}$ and $\left\{\gamma_{n}\right\}$ belonging to $(0,1)$ satisfy (2.1). Then the sequence $\left\{x_{n}\right\}$ converges strongly to an attractive point of $T$.

Proof. It follows from Theorem 2.5 that the sequence $\left\{x_{n}\right\}$ is bounded, the sequence $\left\{\left\|x_{n}-p\right\|\right\}$ is nonincreasing, and

$$
\lim _{n \rightarrow \infty}\left\|x_{n}-p\right\| \text { exists for each } p \in S A(T) \text {. }
$$

We also have

$$
\lim _{n \rightarrow \infty} d\left(x_{n}, T x_{n}\right)=0
$$

In view of Definition 2.4, we obtain

$$
\lim _{n \rightarrow \infty} f\left(d\left(x_{n}, S A(T)\right)\right)=0
$$

which implies

$$
\lim _{n \rightarrow \infty} d\left(x_{n}, S A(T)\right)=0 .
$$

Next, we show that the sequence $\left\{x_{n}\right\}$ is a Cauchy sequence. Indeed, for any $n, m \in N$, without loss of generality, we suppose $m>n$, then

$$
\left\|x_{m}-p\right\| \leqslant\left\|x_{n}-p\right\|, \text { for each } p \in S A(T),
$$

and

$$
\left\|x_{n}-x_{m}\right\| \leqslant\left\|x_{n}-p\right\|+\left\|p-x_{m}\right\| \leqslant 2\left\|x_{n}-p\right\| .
$$

Thus, we obtain

$$
\left\|x_{n}-x_{m}\right\| \leqslant 2 \inf \left\{\left\|x_{n}-p\right\|: p \in S A(T)\right\}=2 d\left(x_{n}, S A(T)\right) .
$$

Combining with (2.2), we get

$$
\lim _{m, n \rightarrow \infty}\left\|x_{n}-x_{m}\right\|=0
$$


Thus $\left\{x_{n}\right\}$ is a Cauchy sequence. Since $X$ is uniformly convex, then there exists $u \in X$ such that

$$
\lim _{n \rightarrow \infty}\left\|x_{n}-u\right\|=0 \text {. }
$$

Then

$$
\lim _{n \rightarrow \infty} d\left(u, T x_{n}\right) \leqslant \lim _{n \rightarrow \infty}\left\|x_{n}-u\right\|+\lim _{n \rightarrow \infty} d\left(x_{n}, T x_{n}\right)=0
$$

It follows that

$$
\lim _{n \rightarrow \infty} d\left(u, T x_{n}\right)=0
$$

Now, we prove $u \in A(T)$. Since $T$ is an $(\alpha, \beta)$-generalized hybrid set-valued mapping, for each $x \in C$, we have

$$
\alpha H^{2}\left(T x_{n}, T x\right)+(1-\alpha) d^{2}\left(x_{n}, T x\right) \leqslant \beta d^{2}\left(x, T x_{n}\right)+(1-\beta)\left\|x_{n}-x\right\|^{2} .
$$

Then

$$
\alpha H^{2}\left(T x_{n}, T x\right)+(1-\alpha) d^{2}\left(x_{n}, T x\right) \leqslant \beta\left[d(x, u)+d\left(u, T x_{n}\right)\right]^{2}+(1-\beta)\|x-u\|^{2} .
$$

Since $d\left(x_{n}, T x\right) \geqslant d(u, T x)-d\left(u, x_{n}\right)$ and $d\left(u, x_{n}\right)<d(u, T x)$ for $n$ large enough, then

$$
d^{2}\left(x_{n}, T x\right) \geqslant\left[d(u, T x)-d\left(u, x_{n}\right)\right]^{2},
$$

which implies

$$
\alpha H^{2}\left(T x_{n}, T x\right)+(1-\alpha)\left[d(u, T x)-d\left(u, x_{n}\right)\right]^{2} \leqslant \alpha H^{2}\left(T x_{n}, T x\right)+(1-\alpha) d^{2}\left(x_{n}, T x\right)
$$

for $n$ large enough. Since $d\left(u, T x_{n}\right) \rightarrow 0$, then there exists $y_{n} \in T x_{n}$ such that $\left\|u-y_{n}\right\| \rightarrow 0(n \rightarrow \infty)$. From the definition of Hausdorff metric, it follows that

$$
H\left(T x_{n}, T x\right)=\max \left\{\sup _{y \in T x_{n}} d(y, T x), \sup _{z \in T x} d\left(z, T x_{n}\right)\right\} \geqslant \sup _{y \in T x_{n}} d(y, T x) \geqslant d\left(y_{n}, T x\right) .
$$

Since

$$
\begin{aligned}
d(u, T x)=\inf _{y \in T x}\|u-y\| & \leqslant \inf _{y \in T x}\left\{\left\|u-y_{n}\right\|+\left\|y_{n}-y\right\|\right\} \\
& =\left\|u-y_{n}\right\|+\inf _{y \in T x}\left\|y_{n}-y\right\| \\
& =\left\|u-y_{n}\right\|+d\left(y_{n}, T x\right)
\end{aligned}
$$

we deduce that

$$
d\left(y_{n}, T x\right) \geqslant d(u, T x)-\left\|u-y_{n}\right\|
$$

Therefore

$$
H\left(T x_{n}, T x\right) \geqslant d(u, T x)-\left\|u-y_{n}\right\|
$$

We notice that $\left\|u-y_{n}\right\|<d(u, T x)$ for $n$ large enough, thus

$$
H^{2}\left(T x_{n}, T x\right) \geqslant\left[d(u, T x)-\left\|u-y_{n}\right\|\right]^{2} .
$$

Combining with (2.3), (2.4), and (2.5), we have

$$
\begin{aligned}
\alpha\left[d(u, T x)-\left\|u-y_{n}\right\|\right]^{2}+(1-\alpha)\left[d(u, T x)-d\left(u, x_{n}\right)\right]^{2} & \leqslant \alpha H^{2}\left(T x_{n}, T x\right)+(1-\alpha) d^{2}\left(x_{n}, T x\right) \\
& \leqslant \beta\left[d(x, u)+d\left(u, T x_{n}\right)\right]^{2}+(1-\beta)\|x-u\|^{2} .
\end{aligned}
$$

Let $n \rightarrow \infty$, we obtain

$$
d^{2}(u, T x) \leqslant\|x-u\|^{2}
$$

which implies

$$
d(u, T x) \leqslant\|x-u\|, \text { for any } x \in C .
$$

Hence $u \in A(T)$. This completes the proof.

Using Theorem 2.5 and demi-compact property, we get the following theorem. 
Theorem 2.7. Let $\mathrm{C}$ be a nonempty closed convex subset of a uniformly convex Banach space $\mathrm{X}$ and let $\mathrm{T}: \mathrm{C} \rightarrow$ $\mathrm{CB}(\mathrm{C})$ be an $(\alpha, \beta)$-generalized hybrid and demi-compact set-valued mapping with $\mathrm{SA}(\mathrm{T})=\mathrm{A}(\mathrm{T}) \neq \emptyset$. Suppose that the sequence $\left\{x_{n}\right\}$ is generated by the iterative scheme (1.2), where $u_{n} \in T z_{n}, y_{n} \in T\left(\left(1-\beta_{n}\right) x_{n}+\beta_{n} w_{n}\right)$, $w_{n} \in T x_{n}$, and $\left\{\alpha_{n}\right\},\left\{\beta_{n}\right\}$, and $\left\{\gamma_{n}\right\}$ belonging to $(0,1)$ satisfy (2.1). Then the sequence $\left\{x_{n}\right\}$ converges strongly to an attractive point of $T$.

Proof. It follows from Theorem 2.5 that the sequence $\left\{x_{n}\right\}$ is bounded and

$$
\lim _{n \rightarrow \infty}\left\|x_{n}-p\right\| \text { exists for each } p \in S A(T),
$$

and

$$
\lim _{n \rightarrow \infty} d\left(x_{n}, T x_{n}\right)=0 .
$$

Noticing that $T$ is demi-compact, there is a subsequence $\left\{x_{n_{i}}\right\} \subset\left\{x_{n}\right\}$ and a point $q \in X$ such that

$$
\lim _{i \rightarrow \infty}\left\|x_{n_{i}}-q\right\|=0 .
$$

Thus

$$
\lim _{i \rightarrow \infty} d\left(q, T x_{n_{i}}\right) \leqslant \lim _{i \rightarrow \infty}\left[d\left(x_{n_{i}}, T x_{n_{i}}\right)+\left\|x_{n_{i}}-q\right\|\right]
$$

which implies

$$
\lim _{i \rightarrow \infty} d\left(q, T x_{n_{i}}\right)=0 .
$$

From the definition of $(\alpha, \beta)$-generalized hybrid set-valued mapping, it follows that

$$
\alpha H^{2}\left(T x_{n_{i}}, T x\right)+(1-\alpha) d^{2}\left(x_{n_{i}}, T x\right) \leqslant \beta d^{2}\left(x, T x_{n_{i}}\right)+(1-\beta)\left\|x_{n_{i}}-x\right\|^{2}
$$

for each $x \in C$. In a similar way to Theorem 2.6, we deduce $q \in A(T)$. Since $\lim _{i \rightarrow \infty}\left\|x_{n_{i}}-q\right\|=0$ and $\lim _{n \rightarrow \infty}\left\|x_{n}-q\right\|$ exists, we get

$$
\lim _{n \rightarrow \infty}\left\|x_{n}-q\right\|=0 .
$$

This completes the proof.

To end this section, we give an example to show that an $(\alpha, \beta)$-generalized hybrid set-valued mapping which fails to be nonexpansive has an attractive point.

Example 2.8. Let $\mathrm{C}=[0,3]$ and $\mathrm{T}: \mathrm{C} \rightarrow \mathrm{CB}(\mathrm{C})$ is defined by

$$
T x= \begin{cases}\{0\}, & \text { if } x \neq 3, \\ {[0.5,1],} & \text { if } x=3 .\end{cases}
$$

We pick $x=\frac{8}{3}, y=3$, then

$$
\mathrm{H}(\mathrm{Tx}, \mathrm{Ty})=\mathrm{H}(\{0\},[0.5,1])=1>\frac{1}{3}=\|x-y\| .
$$

Therefore, $T$ is not a nonexpansive mapping. Let $\alpha=2, \beta=\frac{1}{2}$, we verify that $\mathrm{T}$ is a $\left(2, \frac{1}{2}\right)$-generalized hybrid set-valued mapping, that is,

$$
2 H^{2}(T x, T y) \leqslant d^{2}(x, T y)+\frac{1}{2} d^{2}(T x, y)+\frac{1}{2}\|x-y\|^{2} .
$$

Next, we consider the following four cases:

Case I. Let $x, y \in[0,3)$, then

$$
2 \mathrm{H}^{2}(T x, T y)=2 \mathrm{H}^{2}(\{0\},\{0\})=0 \leqslant d^{2}(x, T y)+\frac{1}{2} d^{2}(T x, y)+\frac{1}{2}\|x-y\|^{2}
$$


Case II. Let $x=3, y \in[0,3)$, then

$$
2 \mathrm{H}^{2}(\mathrm{~T} x, \mathrm{Ty})=2 \mathrm{H}^{2}([0.5,1],\{0\})=2,
$$

and

$$
d^{2}(x, T y)+\frac{1}{2} d^{2}(T x, y)+\frac{1}{2}\|x-y\|^{2}=d^{2}(3,\{0\})+\frac{1}{2} d^{2}(y,[0.5,1])+\frac{1}{2}\|3-y\|^{2} \geqslant 9
$$

Hence

$$
2 \mathrm{H}^{2}(\mathrm{~T} x, \mathrm{Ty})<\mathrm{d}^{2}(x, T y)+\frac{1}{2} \mathrm{~d}^{2}(T x, y)+\frac{1}{2}\|x-y\|^{2} .
$$

Case III. Let $x \in[0,3), y=3$, then

$$
2 \mathrm{H}^{2}(\mathrm{Tx}, \mathrm{Ty})=2 \mathrm{H}^{2}(\{0\},[0.5,1])=2,
$$

and

$$
d^{2}(x, T y)+\frac{1}{2} d^{2}(T x, y)+\frac{1}{2}\|x-y\|^{2}=d^{2}(x,[0.5,1])+\frac{1}{2} d^{2}(\{0\}, 3)+\frac{1}{2}\|x-3\|^{2} \geqslant \frac{9}{2}
$$

Thus

$$
2 H^{2}(T x, T y)<d^{2}(x, T y)+\frac{1}{2} d^{2}(T x, y)+\frac{1}{2}\|x-y\|^{2} .
$$

Case IV. Let $x=y=3$, then

$$
2 \mathrm{H}^{2}(\mathrm{~T} x, \mathrm{Ty})=2 \mathrm{H}^{2}([0.5,1],[0.5,1])=0 \leqslant \mathrm{~d}^{2}(x, \mathrm{Ty})+\frac{1}{2} \mathrm{~d}^{2}(\mathrm{~T} x, \mathrm{y})+\frac{1}{2}\|x-y\|^{2} .
$$

Therefore, $\mathrm{T}$ is a $\left(2, \frac{1}{2}\right)$-generalized hybrid set-valued mapping. For each $x \in[0,3]$, we have

$$
H(T x, 0) \leqslant\|x-0\|,
$$

which implies 0 is an attractive point of $\mathrm{T}$.

\section{Acknowledgment}

This work was supported in part by the National Natural Science Foundation of China under Grants 11401141, Heilongjiang Provincial Natural Science Foundation for Youths under Grant QC2013C001, Heilongjiang Provincial Postdoctoral Science Foundation under Grant LBH-Z15098, and Natural Science Foundation of Heilongjiang Educational Committee under Grant 12531099.

\section{References}

[1] M. Abbas, T. Nazir, A new faster iteration process applied to constrained minimization and feasibility problems, Mat. Vesnik, 66 (2014), 223-234. 1

[2] R. P. Agarwal, D. O'Regan, D. R. Sahu, Iterative construction of fixed points of nearly asymptotically nonexpansive mappings, J. Nonlinear Convex Anal., 8 (2007), 61-79. 1

[3] M. A. Alghamdi, W. A. Kirk, N. Shahzad, Metric fixed point theory for nonexpansive mappings defined on unbounded sets, Fixed Point Theory Appl., 2014 (2014), 12 pages. 1

[4] K. Bolibok, K. Goebel, W. A. Kirk, Remarks on the stability of the fixed point property for nonexpansive mappings, Arab. J. Math. (Springer), 1 (2012), 417-430. 1

[5] J. A. Clarkson, Uniformly convex spaces, Trans. Amer. Math. Soc., 40 (1936), 396-414. 1.2

[6] S. Dhompongsa, T. Domínguez Benavides, A. Kaewcharoen, A. Kaewkhao, B. Panyanak, The Jordan-von Neumann constants and fixed points for multivalued nonexpansive mappings, J. Math. Anal. Appl., 320 (2006), 916-927. 1

[7] S. Dhompongsa, W. Inthakon, W. Takahashi, A weak convergence theorem for common fixed points of some generalized nonexpansive mappings and nonspreading mappings in a Hilbert space, Optimization, 60 (2011), 769-779.

[8] S. Dhompongsa, A. Kaewkhao, B. Panyanak, On Kirk's strong convergence theorem for multivalued nonexpansive mappings on CAT(0) spaces, Optimization, 75 (2012), 459-468. 
[9] S. Dhompongsa, W. A. Kirk, B. Panyanak, Nonexpansive set-valued mappings in metric and Banach spaces, J. Nonlinear Convex Anal., 8 (2007), 35-45.

[10] T. Domínguez Benavides, B. Gavira, Does Kirk's theorem hold for multivalued nonexpansive mappings?, Fixed Point Theory Appl., 2010 (2010), 20 pages. 1

[11] J. García-Falset, E. Llorens-Fuster, T. Suzuki, Fixed point theory for a class of generalized nonexpansive mappings, J. Math. Anal. Appl., 375 (2011), 185-195. 1

[12] K. Goebel, W. A. Kirk, Iteration processes for nonexpansive mappings, Topological methods in nonlinear functional analysis, Toronto, Ont., (1982), 115-123, Contemp. Math., Amer. Math. Soc., Providence, RI, (1983). 1

[13] K. Goebel, W. A. Kirk, Topics in metric fixed point theory, Cambridge Studies in Advanced Mathematics, Cambridge University Press, Cambridge, (1990).

[14] E. Karapinar, P. Kumam, I. M. Erhan, Coupled fixed point theorems on partially ordered G-metric spaces, Fixed Point Theory Appl., 012 (2012), 13 pages. 1

[15] S. H. Khan, I. Yildirim, Fixed points of multivalued nonexpansive mappings in Banach spaces, Fixed Point Theory Appl., 2012 (2012), 9 pages. 1

[16] P. Kocourek, W. Takahashi, J.-C. Yao, Fixed point theorems and weak convergence theorems for generalized hybrid mappings in Hilbert spaces, Taiwanese J. Math., 14 (2010), 2497-2511. 1, 1

[17] F. Kohsaka, W. Takahashi, Fixed point theorems for a class of nonlinear mappings related to maximal monotone operators in Banach spaces, Arch. Math. (Basel), 91 (2008), 166-177. 1

[18] M. A. Noor, New approximation schemes for general variational inequalities, J. Math. Anal. Appl., 251 (2000), $217-229$. 1

[19] K. P. R. Sastry, G. V. R. Babu, Convergence of Ishikawa iterates for a multi-valued mapping with a fixed point, Czechoslovak Math. J., 5 (2005), 817-826. 1

[20] H. F. Senter, W. G. Dotson, Approximating fixed points of nonexpansive mappings, Proc. Amer. Math. Soc., 44 (1974), 375-380 1.1

[21] W. Sintunavarat, P. Kumam, Common fixed point theorems for a pair of weakly compatible mappings in fuzzy metric spaces, J. Appl. Math., 2011 (2011), 14 pages. 1

[22] W. Takahashi, Fixed point theorems for new nonlinear mappings in a Hilbert space, J. Nonlinear Convex Anal., 11 (2010), 79-88. 1

[23] W. Takahashi, Y. Takeuchi, Nonlinear ergodic theorem without convexity for generalized hybrid mappings in a Hilbert space, J. Nonlinear Convex Anal., 12 (2011), 399-406. 1

[24] W. Takahashi, J.-C. Yao, Fixed point theorems and ergodic theorems for nonlinear mappings in Hilbert spaces, Taiwanese J. Math., 15 (2011), 457-472. 1

[25] H.-K. Xu, Inequalities in Banach spaces with applications, Nonlinear Anal., 16 (1991), 1127-1138. 1.3

[26] Y.-C. Zheng, Attractive points and convergence theorems of generalized hybrid mapping, J. Nonlinear Sci. Appl., 8 (2015), 354-362. 1 